\section{Is Culture Necessary before First-Line Treatment for Helicobacter pylori Infection?}

Key words: Helicobacter pylori, susceptibility testing, antibiotic

\section{(Intern Med 50: 2719-2720, 2011) \\ (DOI: 10.2169/internalmedicine.50.5974)}

The Authors Reply We want to thank Dr. Gisbert et al for their insightful comments on our article. They have raised a number of important points which must be addressed. We do agree that it is premature to recommend culture before first-line treatment for all patients with Helicobacter pylori (H. pylori) infection.

We agree with the authors that antimicrobial susceptibility testing has some limitations, such as, it is expensive, timeconsuming, and often means the procedure of endoscopic exploration, etc.

However, we have to admit the following has been recognized widely:

1) About one-half of the world human population is infected with $H$. pylori that is the most recognized etiological risk factor for gastric cancer (GC) and its precursors (1). The prevalence of $H$. pylori infection varies between countries, even within a single country it varies between the subpopulations, being several times higher in some ethnic groups $(2,3)$.

2) The global burden of GC is considerable; it remains the second most common cause of cancer death, but varies geographically. Nearly two-thirds of this burden is borne by Eastern Asia, Eastern Europe and Central and South America (2). These geographical locations also show a high prevalence of $H$. pylori infection and eradication of $H$. pylori infection has the potential to reduce the risk of GC development. The issue is emotive as there is understandable patient and doctor fear related to it (4).

3 )The resistance rate varies geographically (5). One study showed the resistance rate to clarithromycin, metronidazole, fruranzolidone and amoxicillin was $8.3 \%, 94.4 \%, 16.7 \%$ and $33.3 \%$, respectively, in Zhejiang adolescents of China (6). Kim et al reported that the resistance to clarithromycin varies from $12.5 \%$ to $42.1 \%$ in three institutes of South Korea (7). However, it has been recommended that the threshold of clarithromycin resistance at which this antibiotic should not be used, or a clarithromycin susceptibility test should be performed, is $15-20 \%$ (3).

Some antibiotics have begun to show resistance, which was rarely reported previously. Even new antibiotics have joined the resistance club at an alarming rate. For example, the resistance rates of $H$. pylori to levofloxacin $(10.3 \%$, $24.0 \%$ and $32.5 \%$ ) have increased from 2000 to 2009 in Shanghai (8).

4) It is accepted that the overall efficacy of the standard triple treatment has markedly declined mainly due to antibiotic resistance; in some areas it has reached alarming levels $(60-80 \%)$. However, it has been recommended that treatment should achieve an eradication rate of $>80 \%$ (3).

5) Sequential therapy is a promising therapy (9-11), but the effects still remain controversial in some countries (12-15), thus further trials are needed in other European countries and North America. As far as we know, one potential mechanism by which sequential therapy achieves superior eradication rates is that the organism is exposed to all of the key antibiotics together we have currently available. If it fails one day, what should we do?

6) The past experience seems to indicated that it is not as efficacious anymore as previous expectations, and actually, the choice of initial therapy is in a state of flux. Therefore a variety of methods must be used to achieve successful eradication. It is the same as in other infectious diseases, theoretically, the destruction should be directly targeted rather than by merely using a "hit or miss" process. Susceptibility testing is still the gold standard to separate susceptible and resistance strains, although it still needs technical improvement (16).

7) A new method gives us new hope. Molecular methods of detection of specific changes in the organisms' genome are alternative approaches to detection of resistance and in theory allow a more rapid detection of resistance as well as detection of resistance using stool or biopsy specimens (17).

For the above-mentioned reasons, individual treatment should be advocated. For example, macrolide susceptibility testing by culture or molecular methods is now necessary before prescribing clarithromycin, due to the high prevalence and big gap of this resistance (18).

Anyway, the picture is still far from clear, clinicians need to carefully consider the currently available options for the treatment of $H$. pylori. Susceptibility testing should be taken into account, which is the most rational option but it is currently not used widely enough, particularly in the high gastric cancer risk population in high antibiotic resistance regions. And more well-designed, double-blind, and wide ranging geographical RCTs are still needed.

My Commentary can only serve as an introduction to the complex issue of $H$. pylori treatment. It may also, provide

${ }^{1}$ The First Hospital of Lanzhou University, China and ${ }^{2}$ The Second Hospital of Lanzhou University, Key Laboratory of Digestive System Tumors, China

Received for publication June 8, 2011; Accepted for publication June 14, 2011

Correspondence to Dr. Li Yumin, liyumin168@yahoo.com.cn 
stimulus for debate and action on this important issue.

We are thankful to the authors of this letter for giving us an opportunity to make some points more clear.

\section{The authors state that they have no Conflict of Interest (COI).}

\section{Acknowledgement}

This study was founded by Natural Science Foundation of China (No.30870364), and not funded by any Pharmaceutical Company. The authors would like to thank James R. Claflin, M. D., Mrs. Marcee Claflin and Christian M. Ellis, DO for editorial assistance.

Yuan Wenzhen ${ }^{1}$, Zhao Peng ${ }^{1}$, Guan Quanlin ${ }^{1}$ and Li Yumin ${ }^{2}$

\section{References}

1. Eslick GD. Helicobacter pylori infection causes gastric cancer? A review of the epidemiological, meta-analytic, and experimental evidence. World J Gastroenterol 12: 2991-2999, 2006.

2. Fock KM, Katelaris P, Sugano K, et al. Second Asia-Pacific Consensus Guidelines for Helicobacter pylori infection. J Gastroenterol Hepatol 24: 1587-1600, 2009.

3. Malfertheiner P, Megraud F, O'Morain C, et al. Current concepts in the management of Helicobacter pylori infection: the Maastricht III Consensus Report. Gut 56: 772-781, 2007.

4. Konturek PC, Konturek SJ, Brzozowski T. Gastric cancer and Helicobacter pylori infection. J Physiol Pharmacol 57 Suppl 3: 51-65, 2006.

5. Konturek PC, Konturek SJ, Brzozowski T. Helicobacter pylori infection in gastric cancerogenesis. J Physiol Pharmacol 60: 3-21, 2009.

6. Huang LP, Zhuang ML, Gu CP. Antimicrobial resistance of 36 strains of Helicobacter pylori in adolescents. Zhongguo Dang Dai Er Ke Za Zhi 11: 210-212, 2009 (in Chinese).

7. Kim JY, Kim NY, Kim SJ, et al. Regional difference of antibiotic resistance of Helicobacter pylori strains in Korea. Korean J Gastroenterol 57: 221-229, 2011 (in Korean).

8. Sun QJ, Liang X, Zheng Q, et al. Resistance of Helicobacter py- lori to antibiotics from 2000 to 2009 in Shanghai. World J Gastroenterol 16: 5118-5121, 2010.

9. Schmiloviz-Weiss H, Shalev T, Chechoulin Y, et al. High eradication rates of Helicobacter pylori infection following sequential therapy: The Israeli experience treating naive patients. Helicobacter 16: 229-233, 2011.

10. Tursi A, Elisei W, Giorgetti G, Picchio M, Brandimarte G. Efficacy, tolerability, and factors affecting the efficacy of the sequential therapy in curing Helicobacter pylori infection in clinical setting. J Investig Med Mar 25, 2011 [Epub ahead of print].

11. Gatta L, Vakil N, Leandro G, Di Mario F, Vaira D. Sequential therapy or triple therapy for Helicobacter pylori infection: systematic review and meta-analysis of randomized controlled trials in adults and children. Am J Gastroenterol 104: 3069-3079, 2009; quiz 1080 .

12. Nadir I, Yonem O, Ozin Y, Kilic ZM, Sezgin O. Comparison of two different treatment protocols in Helicobacter pylori eradication. South Med J 104: 102-105, 2011.

13. Güzelbulut F, Sezikli M, Akkan Cetinkaya Z, et al. Application of levofloxacine in the second phase of sequential therapy regimen for Helicobacter pylori eradication: is it a good choice? Minerva Med 102: 171-176, 2011.

14. Mahachai V, Sirimontaporn N, Tumwasorn S, Thong-Ngam D, Vilaichone RK. Sequential therapy in clarithromycin-sensitive and -resistant Helicobacter pylori based on polymerase chain reaction molecular test. J Gastroenterol Hepatol 26: 825-828, 2011.

15. Aminian K, Farsad F, Ghanbari A, Fakhreih S, Hasheminasab SM. A randomized trial comparing four Helicobacter pylori eradication regimens: standard triple therapy, ciprofloxacin based triple therapy, quadruple and sequential therapy. Trop Gastroenterol 31: 303307,2010

16. Graham DY, Shiotani A. New concepts of resistance in the treatment of Helicobacter pylori infections. Nat Clin Pract Gastroenterol Hepatol 5: 321-331, 2008.

17. Moder KA, Layer F, Konig W, Konig B. Rapid screening of clarithromycin resistance in Helicobacter pylori by pyrosequencing. J Med Microbiol 56 (Pt 10): 1370-1376, 2007.

18. Megraud F. Helicobacter pylori: bacteriological aspects, diagnostic methods, and susceptibility to antibiotics. Presse Med 37 (3 Pt 2): 507-512, 2008.

(C) 2011 The Japanese Society of Internal Medicine http://www.naika.or.jp/imindex.html 